\title{
Top-Level Design and Practical Applications of Wisdom Campus in Chinese University-A Case of Wisdom Beihang
}

\author{
Qingshan $\mathrm{Xu}^{1,2,{ }^{*}}$, Jianhua Zhang ${ }^{3}$, Lihua Yang ${ }^{1}$ and Liu Zhang ${ }^{1}$ \\ ${ }^{1}$ College of Public Administration, Beihang University, Beijing, China \\ ${ }^{2}$ Office Automation Technology Center of Gansu, Gansu, China \\ ${ }^{3}$ Network Information Center, Beihang University, Beijing, China \\ Corresponding Email: xuqs@buaa.edu.cn
}

\begin{abstract}
Wisdom education is the direction of educational informatization development. Wisdom campus is the advanced stage of the development of educational informatization. The construction of wisdom campus is a complicated systematic project, requiring not only strengthening top-level design from the macro level, but also considering the specific operational implementation from the micro level. On the background and connotation of wisdom campus development, this paper reviews the domestic research literature, and analyses the top-level design of wisdom campus. The organization structure is the key; the business process is the main line; the institution standard system is the focus; the campus culture is the essence; the platform construction is the core; the public service is the target; the operation and maintenance is the support; the information security is the basis; the supervision and assessment is the guarantee. At the same time, combined with the practical application of wisdom campus construction of Beihang University, the One-card service, integrated services, One-stop service, wireless network, unified identity authentication, data center, and iHome comprehensive application platform provide a reference case for the top-level design and construction of wisdom campus.
\end{abstract}

\section{Introduction}

With the deepening of the continuous development of information technology and educational reform, the educational informatization in our country has experienced changes from traditional campus to the stage of digital campus, and then moves towards a new stage of construction of the wisdom campus. Educational informatization has been gradually showing characteristics of digital, network, platforms, intelligence, open, and social networking. Wisdom campus has become the theme and the trend of the current development of educational informatization. The informatization of university is the priority among priorities of practice and development in national educational informatization, being an important indicator of a country's education level, and furthermore an important manifestation of a country's comprehensive competitiveness.[1] How to improve the informatization and intelligence level in the education field, especially making the top-level design and practical application of the wisdom campus, and how to develop with wisdom medical service, transportation, community and city at the same pace are real problems and great challenges in the development of wisdom education.

There are few dissertations and core journal papers on the study of wisdom campus in China. As of December 2015 , there are 123 papers on wisdom campus searched in the CNKI, among which 2 papers are doctoral dissertations, 60 papers are master's dissertations, and 61 papers are core journal in the Chinese Social Sciences Citation Index (CSSCI), as shown in Table.1. Overall, it shows a trend of rapid growth year by year.

Table.1 Annual statistics of wisdom campus paper.

\begin{tabular}{|l|l|l|l|l|l|l|l|}
\hline Name & 2010 & 2011 & 2012 & 2013 & 2014 & 2015 & Sum \\
\hline $\begin{array}{l}\text { doctoral and } \\
\text { master's } \\
\text { dissertations }\end{array}$ & 0 & 0 & 4 & 10 & 25 & 23 & 62 \\
\hline
\end{tabular}




\begin{tabular}{|l|l|l|l|l|l|l|l|}
\hline $\begin{array}{l}\text { CSSCI } \\
\text { journals }\end{array}$ & 1 & 3 & 14 & 6 & 16 & 21 & 61 \\
\hline total & 1 & 3 & 18 & 16 & 41 & 44 & 123 \\
\hline
\end{tabular}

These papers can be divided into engineering technology category, education and management category, educational technology category and others category according to subject classification. According to this classification, there are 60 papers $(49 \%)$ in the engineering technology category, 14 papers $(11 \%)$ in the education and management category, 17 papers $(14 \%)$ in the educational technology category, and 32 papers $(26 \%)$ in others category.(see Figure 1$)$ These analysis show that we have paid more attention to the technical attributes of wisdom campus in a long time, but not enough to the educational attributes and the top-level design. So the biggest obstacle is the top-level design and management mechanism, rather than the technology in the construction to promote the process of wisdom campus. Thus, we should put greater emphasis on researches about the design and mechanism of wisdom campus.

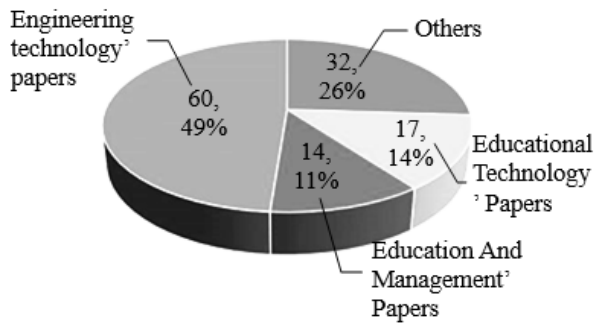

Fig. 1. Statistics in subject classification of wisdom campus.

\section{The background of wisdom campus development}

In 1970s, Massachusetts Institute of Technology firstly proposed the "Electronic Campus"(E-campus) program. In 1990 , Kenneth C. Green, a professor of Claremont University, firstly proposed the concept of "Computing Campus", and presided over the Campus Computing Project(CCP) research projects, opening the pace of educational informatization construction in the world and providing a lot of digital campus experience for other countries [2]. Since the implementation of CCP, in the year from 1996 to 2010, the United States government has promulgated and implemented four national "Educational Technology Program". These programs adopts a joint model that the government, schools and enterprises work together. It enables every student to use the computer, every classroom to access the Internet, and every youth to receive higher education which is made through Internet. It achieves the connection of "Person, Machine, Road, Net" from the primary school to university. It completely changed the way, means and process of education and learning in university education in the United States. And then the U.S. educational informatization has always been in the leading position in the world. The U.S. has also esTablelished the world's most influential institution EDUCAUSE to lead the development direction of education informatization [3]. Information technology in American education has experienced a transformation process from the infrastructure construction to system application, to practical effect, and then to adjust the structure. It has always followed the strategic policy of "Information Technology to Promote Education Reform and Development". The development process of American educational informatization has been gradually developing from the electronic campus to digital campus, and then to the wisdom campus [4].

The Britain, Australia, New Zealand, and Japan, have also formulated and implemented a series of educational informatization promotion program [5]. For example, Britain has released the Super JANET and 2010-2012 Educational Development Strategy. Australia has the Building the Education Revolution(BER). New Zealand has the Information and Communication Technologies Professional Development(ICTPD) and An E-Learning A ction Plan for School(2006 -2010). Japan has e-Japan, u-Japan and i-Japan. In the European Union, the Comenius Program is implemented for the basic education, the Socrates Program for the higher education, the Leonardo Da Vinci Programme for vocational education. etc [6]. These programs and strategies provide a typical reference and experience for other countries regarding the transformation from digital campus to wisdom campus.

Educational informatization of university in China has been influenced by foreign factors, and also has experienced from the electronic campus to digital campus and then to the wisdom campus. The China Education Technology Network(CERNET) was officially opened in 1995, which not only achieved the interconnection between province level, but also laid the foundation for the esTablelishment of electronic campus. In 2004, the New CETNET(CERNET 2) using IPv6 was built [7]. Chinese has made strategy of The Education Promotion Motion Plan(2003-2007). On the one hand, it could accelerate the development of education information technology infrastructure construction and construction of information resource. On the other hand, it could promote the construction of digital campus in universities, using change traditional teaching methods and models to improve the information level of education. In 2006, the Chinese Ministry of Education set up the office of educational information, which was responsible for the toplevel design and unified management of various types of education information construction. On July 29th 2010, Ministry of Education issued The Reform and Development Plan Outline of National Long-Term Education(2010- 
2020), which has included education information into the national information development strategy [8]. These plans have accelerated the construction of digital campus, improved the educational information system, and promoted the modernization of educational content, means and methods. Zhejiang University was the first one which put forward the wisdom campus construction among domestic universities. Its goal is green and energy conservation, peace and coordination, scientific decision-making, and convenient service [9]. Nanjing University of Posts and Telecommunications, Tongji University, Tsinghua University, Beijing University and Beihang University have put forward the construction of wisdom campus.

\section{The connotation of wisdom campus}

So far, there is no accurate and scientific definition of "wisdom campus". Experts and scholars in different fields have different understanding of it. From the perspective of education, the principle of wisdom campus is to provide personalized service to students and teachers. Through the system, we can be fully aware of the physical environment, identify the learners' individual characteristics and learning situation, and use information technologies to provide an open learning environment, a comforTablele living environment and rich campus culture [10]. These are the starting point and destination of the wisdom environment, wisdom teaching and wisdom learning, which eventually aims at developing the wisdom of the students [11]. From the perspective of information technology, benefited from the development of new technology, wisdom campus is an open, interactive and collaborative integrated service platform featuring informationized and intelligent, with the technology of internet, cloud computing and internet of things, providing the intelligent service with numbers on the internet $[12,13]$. In this way, the majority of teachers and students are able to acquire comprehensive teaching information, effectively share data resources, making the teaching activities and common life more convenient $[14,15]$.

To sum up, wisdom campus is a broad concept. It generally describes a system combining "technology, education, management, service and ideas".(see Figure 2) Wisdom campus is based on infrastructures of educational informatization, collecting and integrating all kinds of educational information resources with the use of cloud computing, network of things, big data, virtual technology, sensor technology and mobile communication technology of a new generation of information technology. It focuses on wisdom service to diversified customers, including students, teachers, administrative staffs, alumnus, parents, and the public. Guided by teaching, learning, researching, using, management and other business needs, we build a digital, networking, integrated, collaborative, amalgamation, comprehensive, personalized and intellectualization resources platform. We hold the beliefs of innovation, coordination, green, open and sharing, deeply combine technology, education, management, system and culture, to esTablelish a new integrated educational model capable of providing wisdom learning, teaching, scientific research, applications, social interacts, management, decision-making, services and life. It will be a new wisdom environment in the campus, which is convenient for learning, teaching, working and social life.

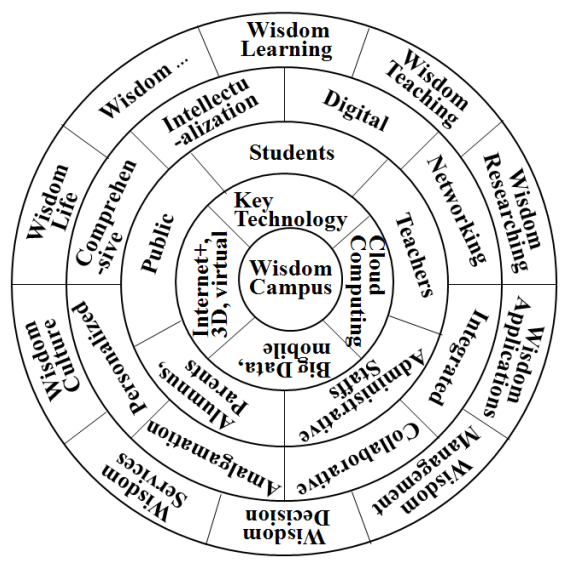

Fig. 2. Logical relation of the wisdom campus connotation.

\section{The Top-Level Design of Wisdom Campus}

As an engineering concept, the top-level design, with the system theory method, is to make an overall plan on a task or project, making considering of all the facts and elements. Thus, we can focus on the advantages of resources, to achieve the goal in an efficient way [16]. Top-level framework of the U.S. E-government Federal Enterprise Architecture(FEA) consists of five parts [17]: strategic business planning reference model(BRM), data standard reference model(DRM), technical framework reference model(TRM), service reference model (SRM), performance evaluation reference model(PRM). 
Construction of the wisdom campus is not a simple information-engineering project, but a complex engineering system, combining information technology of the new generation with education, management, system and culture, which needs to strengthen top-level design from the overall situation. Wang Yukai, an information expert, believes that the top-level design is the specification of overall planning, a means of implementation of the overall plan [18]. The top-level design of wisdom campus comprehensively considers all aspects of environmental factors in technology, business, management, service, mechanism and culture as a whole, in order to make comprehensive and systematic planning and design. There should be coordination, matching, integration and support, between the various environment elements. The design sticks to the principle of "unified planning, intensive construction, unified deployment, resource sharing, unified implementation, and result oriented". It is a designing process combining the method of "from above to below" and the operational implementation of "from below to above", featuring top-level decision-making, operational, unified specification and overall coordination. Specifically, the overall structure of the top-level design of the wisdom campus includes nine systems that are organizational structure, business processes, institution standard, campus culture, platform construction, public service, operation and maintenance, information security, supervision and assessment.(see Figure 3)

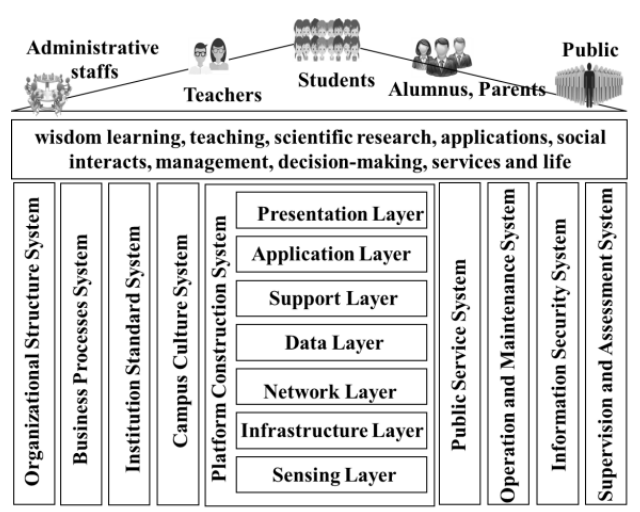

Fig. 3. Top-level design framework of the wisdom campus.

\subsection{Organizational structure system is the key}

Organizational structure system is the organizational structure, functional responsibilities and coordination mechanisms to promote the construction of wisdom campus, including systems of leadership decision-making, implementation and expert consultation. Leadership decision-making system is on the leadership and decision-making level, in charge of making decisions and coordination management of major issues. The implementation system is on the implementation level, responsible for the construction of wisdom campus construction and implementation of the specific work. Expert advisory system is on the auxiliary decision-making level, responsible for providing supplementary decision-making and professional support. The system of wisdom campus in Beihang University is made of the information management committee, executive team and the expert advisory committee composition(see Figure 4), which forms two levels of information management mechanism. The information management committee by the president, executive vice president and the leaders of each department is mainly responsible for the overall planning of information and the toplevel design of the wisdom campus. It is in charge of the information technology management office (often set in the network information center), mainly responsible for the coordination and management work. The information implementation group is staffed by directors of the network information center and other departments, working on works about information and the building, implementation and application of the wisdom campus. Information expert advisory committee by the professor, senior engineers and external experts, provides auxiliary advices and solid support for the planning, construction and implementation of information issues.

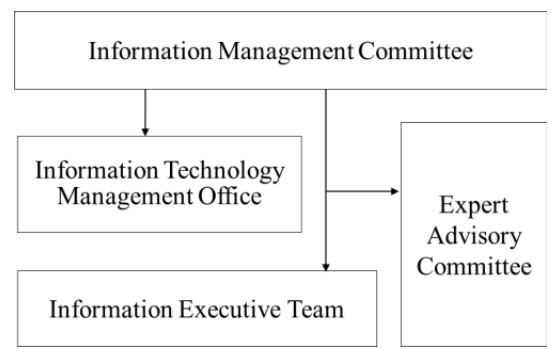

Fig. 4. The organizational structure system of wisdom campus in Beihang University. 


\subsection{Business process system is the main line}

The process of business contains procedures of cooperation and undertaking between different departments with diversified business. It is transforming the known issue into events that is valuable to the customers.[19] The business process system is to simplify, refine, re-simplify, and re-define the business according to actual needs of each department, each job and each character. By constructing a wisdom business processing system, unified, scientific, standard and formal, satisfying needs and corresponding to reality, we can finally realize the reinventing of business process and reusing of information. The business process system of Beihang University is based on basic business needs of the university. It draws lessons from life cycle management of business process management (BPM) in enterprise resource planning (ERP) to define different kinds of business, set up models, make simulations, and launch the project, and then followed by monitoring, analyzing and optimizing it. Setting up examples based on BPMN2.0, the system ensures every unit of business and event to be quantified and standard, thus, it enables every part of the process to be optimized, instead of only part of the process.

\subsection{Institution standard system is the key point}

Institution standard system includes standards, systems and mechanisms of techniques, management and services. From the technical level, we need to make sure that the information collection, data processing, data exchange and data analyses are qualified in standards, and that the data structure and the data interface are suiTablele for each other. Therefore, it can satisfy the need of data exchange and lay a solid foundation for data integration and resource sharing. From the management level, we need to esTablelish regulations and systems of the project planning and design, engineering implementation management, information resource management, system processing management, information security management, performance assessment, in order to improve the intelligent level of management. From the service level, according to the actual business needs of teaching, learning, researching, using and management, we esTablelish a people-oriented wisdom service concept in order to upgrade the level of intelligence services. In terms of policy standards, the wisdom campus of Beihang University formulated management systems of informatization project, methods of operation and maintenance management, network and information security measures. We have assured the technical standards of the data structure, business architecture, technical architecture, and application architecture, compiled the technical manual and operation guidelines of different systems, as well as Chief Information Officer (CIO) system, personnel training system, performance appraisal system and so on.

\subsection{Campus culture system is the essence}

Campus culture is created in the long-term education practice process of a school, reflecting the school values, thinking methods and behavior norms, embodying the common belief and spiritual pursuit of all teachers and students. It is a spiritual force to hold all parts of the school together [20]. In the age of information technology rising up, human wisdom and environment interact with each other. Under the circumstances like that, wisdom culture inherited the traditional spirit of the campus and formed innovation culture with characteristics of network culture, reflecting advanced campus spirit and cohesion of "positive energy" of the era. As a subset of the construction of campus culture, the construction of wisdom campus is a like tool for the development of campus culture, and it is the only way to school education and culture [21]. Campus culture system mainly includes four aspects that are material culture, system culture, behavior culture and spiritual culture. The wisdom campus of Beihang University formed unique wisdom culture, such as the small "i" culture, the culture of the wisdom website, and the new media culture.

\subsection{Platform construction system is the core}

The platform construction system includes perception layer, infrastructure layer, network layer, data layer, support layer, application layer and presentation layer. (1)Sensing layer is to use sensors, RFID (Radio Frequency Identification), twodimensional code, 3D printing, camera, etc., for the realization of the overall perception between "human - machine materials". (2)Infrastructure layer includes server storage devices, network security equipment, terminal equipment, cloud platform equipment, computer rooms and teaching and office spaces, etc. (3)Composed of the campus wired network, wireless network, mobile network, Network layer refers to private cloud, public cloud, mixed cloud, and wisdom cloud. (4)Data layer includes all kinds of business daTablease, data warehouse, resource daTablease, information resource catalog, data backup and remote storage, etc. (5)The support layer includes components of shoring of foundations, service support, public support, and a unified support platform. (6)Application layer refers to all kinds of business application software system serving in teaching, scientific research, management, service and life. (7)The presentation layer is to provide personalized information service through the website, students or teachers' home page, micro-blog, WeChat and Weibo for teachers, students and the public. Based on the cloud platform and to meet all kinds of business needs, as in teaching, learning, researching, using and management, the wisdom campus of the Beihang University built corresponding software system platforms, such as systems for teaching, scientific research, finance, personnel, assets, logistics, office, school, enrollment, employment and iHome integrated application platform. 


\subsection{Public service system is the goal}

Public service is an important measure to improve the overall teaching, scientific research, management and service level of colleges and universities, and it is also an important way to improve the comprehensive strength and core competitiveness of colleges and universities [22]. The public service system of the campus includes education resource services such as the library, online education, scientific research equipment, infrastructure, students' service, sports, talent recruiting, culture and information security. Constructing the public service system of the wisdom campus can effectively promote the education reform and the transformation of college management and service mode. Specifically, it is to transform services from face-to-face to online service, from the single service to the diversified, from the passive service to active, from facing the campus to the outside, from the school service to the social service. The public service system of wisdom Beihang University adopted the exploration of "1+1" mode and "The Belt and Road" mode, to unite the related colleges and universities. Also, we use wisdom campus platform to provide wisdom public services to the school and the society. Among the services are the books, scientific research, online education, information technology, talent, culture, etc.

\subsection{The system of operation and maintenance is the support}

Operation and maintenance system includes organizing personnel, processing, systems, supporting platform and management object, etc [23]. The organizational structure and personnel of operation and maintenance is to have a dedicated organizations and specialized team in accordance with the different professionals and different levels of security personnel. Operation and maintenance process is to develop a standardized workflow, to ensure that the operation and maintenance carried out in order and the operation problem to be solved. The system of operation and maintenance requires a series of management system, to ensure that the operation and maintenance is efficient and coordinated. The operation and maintenance platform refers to various software platforms that are applied in the work. The objects in the management consist construction of infrastructure, business application systems, daTablease, information resources and staff of operation and maintenance. The wisdom campus of Beihang University esTablelished the unified management system for the operation and maintenance personnel, technology, resources, processes and institutions, by way of centralized monitoring, collaborative linkage, responsible classification and standard service. It provides $24 / 7$ services, providing a safe and reliable environment for the planning, construction, implementation and management of the wisdom campus.

\subsection{Information security system is the foundation}

Information security system consists of physical security, network security, data security, application security, content security, user security and safety management, etc [24]. Physical security includes safety equipment, medium security, backup and disaster recovery, electricity safety; network security including access security, risk assessment, antiintrusion detection, anti- virus attacks, security rank protection, etc. Data security includes daTablease security, data encryption, digital authentication, digital signature, data audit and so on. Application security includes security monitoring and warning, emergency response and security policy planning, etc. Content security contains information filtering, privacy protection, classified information management; user security consists user authentication, access permissions. Safety management includes the safety management system, safety organizations and responsibilities, security emergency measures, etc. The wisdom campus of the Beihang University strengthens organization, management, technology and applications from multiple levels, with the use of the firewall, anti-virus, intrusion detection, unified authentication, network auditing, data encryption, access control, virtual private network (VPN) and other key technology to guarantee the information security.

\subsection{The system of supervision and assessment is for guarantee}

The evaluation index of information supervision in universities is an important tool to measure the construction, application and development of the wisdom campus. It has the characteristics of skopos, targeted, systematic, scientific, operational and dynamic [25]. The system of supervision and evaluation includes development strategy status, organization management and guarantee, infrastructure construction, information talent construction, information resources construction, information technology application, information security and so on. Combining with the actual characteristics of the university, the wisdom campus of Beihang University developed detailed assessment indicators that consist the top-level design, organization and management, infrastructure, information resource, data center, web application, application for the system, information security, information management, process management, talent construction and system construction. With information openness, resource sharing, online services, online evaluation, network supervision as means of information, supervision and evaluation, it enables us to achieve wisdom supervision and assessment of the campus.

\section{Practical applications of wisdom campus}




\subsection{One-card service}

One-card service is one of the most important applications of Wisdom Beihang, and it is the combined application of integration, networking, amalgamation and intelligentization. The background of Wisdom Beihang One-card system is a complex system composed of hardware system, software system, daTablease, data exchange platform, terminal, etc. It is the integration of cards, licenses, Tableles, bills and tickets (e.g. Student ID card, library card, dining card, bath card, electric card, water card, access card, attendance card, commuter card, medical card, payment card, consumer card, etc.). In addition, the multi-application of one card in certification, management, service, consumption and finance is completed so that "One card in hand, No worry in campus" is achieved. The application of One-card is throughout the whole life cycle and every aspect required by teachers and students from entering to leaving the school. By sharing various types of data to solve the information isolated island problem, using various types of resources to avoid repeated construction, integrating various tapes of business demands to improve the quality and efficiency of teaching, optimizing various types of process standards to improve management and service levels, the One-card provides teachers and students with convenient, efficient and satisfactory Intelligent service in study, work and life.

\subsection{Integrated service}

Integrated service is one of the most unique services in Wisdom Beihang. This service can be in the form of integrating virtual online service hall and Entity service hall. It has effectively helped teachers and students solve "shuttle run problem" and "circle run problem" during studying, working and living. Moreover, the quality of school integrated management and public service have been enhanced. Wisdom Beihang esTablelished service hall of teachers and students, logistics service hall and financial settlement center. Meanwhile, it also appointed various functional departments moving into service hall. These service halls provide services including the school seal, status management, graduate, abroad, employment, household, scientific research, personnel, accommodation, logistics, tuition and financial. The online service hall, on the other hand, provides integrated online services. A seamless transition between online and offline services is the combined embodiment of intelligent service and integrated Service of Wisdom Beihang.

\subsection{One-stop service}

Portal website is an important platform for universities to do information releasing, image promoting, brand displaying and service supplying. It is also an important "window" and "face" for first-class universities. By using advanced design concepts, sophisticated technology and a complete website management system, Wisdom Beihang has constructed a one-stop service website group management system based on cloud platform. This one-stop platform polymerizes various types of resources in the way of Web2.0, supports website group data ESB(Enterprise Service Bus) and distributed deployment. Meanwhile, this background system of one-stop platform mainly adopts CMS(Content Management System). One-stop service of Wisdom Beihang has not only realized portal site's intensive construction of various faculties and departments by unified standards, unified planning, unified framework, unified release, unified management, and unified maintenance, but it has also solved the problem of coordinating standards, capital, personnel, management, maintenance and safety in order to esTablelish a new management and service mode of website group with the characteristics of one-net and one-stop.

\subsection{Wireless network}

Wireless network of Wisdom Beihang construction mainly uses WiFi(Wireless Fidelity) and mobile internet technology. Combined with the wired network, it has achieved full coverage on teaching building, office buildings, laboratory buildings, dormitories, libraries, restaurants and other places in two campus (Beihang Xueyuan Road Campus and Shahe Campus).Wireless network realizes following functions: in the aspect of scale, it achieves the WiFi coverage of every corner of the campus; in terms of speed, it achieves the high speed and high quality transmission; in the view of the conformity, it achieves interconnection, intercommunication and sharing between wireless network and wired network; in the perspective of application, it enables wireless network to carry all kinds of business application system; in the aspect of using, it supports mobile PDA, Tablelet PCs, smart phones and other types of mobile terminal equipment. Wireless Network of Wisdom Beihang has broken through the boundaries of space, and provides teachers and students with a convenient, simple, personalized, safe, reliable, sTablele, efficient and lightweight mobile intelligent services.

\subsection{Uniform identity authentication system (UIAS)}

Based on the unified coding rules, unified technical standards and unified process specifications, Wisdom Beihang UIAS mainly uses SSO (Single Sign-On) and LDAP (Lightweight Directory Access Protocol), and its interface supports JAVA, C, C\#, PHP and several other languages. By using unique user name and password to log on different business application system, the system provides users with the only electronic identity authentication from the interface layer, data layer application layer, and other layers, realizing the unified identity authentication and 
management based on 4A specification (Authentication, Account, Authorization, Audit). Furthermore, Wisdom Beihang UIAS, unified portal site and unified public data exchange platform have been put together to implement SSO and DS(Data Synchronization) in order to achieve the true meaning of the unified identity authentication.

\subsection{Data center}

Data center is the most importance in Wisdom Beihang, and it's also one of the important contents of Beihang University 13th Five-Year informatization planning. Wisdom Beihang uses cloud computing and virtualization technology to set up a virtual data center architecture. Taking advantage of this architecture, it can realize the hardware resources, network resources, and data storage resources in comprehensive integration. In addition, it can optimize the computing pool, storage pool, network pool, security pool, application pool, and resource pool in an all-sided way. Furthermore, the data center has implemented full virtualization, a high degree of integration and optimization of all kinds of resources sharing. The Wisdom Beihang Data Center, which consists of the storage infrastructure, data acquisition system, data exchange platform, intelligent analysis system, intelligent decision-making system, etc., processes, prepares, analyzes and mines deeply on multi-sources data (e.g. teaching, scientific research, experiment, archives, books, management, service, talent, international cooperation, and other multi-source data). Eventually, "speaking with data", "deciding by data", "managing by data" and "innovating by data" has been achieved, and data is used as a strategic resource for Wisdom Beihang to provide safe and reliable support.

\section{7 iHome integrated application platform}

Wisdom Beihang has constructed a comprehensive application platform "iHome" with the concept of "Internet+". "iHome+ Teaching" integrates online courses center, course record system, cloud video center, student educational system, teaching evaluation system and others to achieve the function of online education. "iHome+ Management" integrates student management system, personnel management system, financial management system, asset management system, online office system and others to achieve the coordination management functions on arranging human, financial, material, and other things. "iHome+ Service" integrates enrollment and employment system, household registration security system, medical treatment system, online payment system, logistics service system and scientific research reporting system to achieve online service functions. "iHome+ Community Spaces" integrates personal homepage of teachers and students, communicating space, BBS, academic forum, club activities to accomplish online community and online communication. iHome of Wisdom Beihang shows the personalization features of "Internet+ Education", and it reflects the important features of wisdom campus including digitalization, networking, integration, collaboration, amalgamation, integration, personalization, intellectualization etc.

\section{Conclusion}

Based on the new information technology, such as the cloud computing, Internet of things, big data and mobile Internet, and learning from the experience and outcomes of the construction of digital and wisdom campus in domestic and the world, the top-level design of it can be strengthed from multi-levels, including technique, business, management, standard, institution and security. At the same time, we are ought to make constant innovations in building many wisdom platforms of the colleges and universities, featuring digital, networking, integrated, collaborative, amalgamation, comprehensive, personalized and intellectualization, in order to make learning, teaching, scientific researching, applications, management, decision-making, services, and normal life more intelligent. All those above are the final goal of the construction of wisdom campus of colleges and universities, and the irresistible trend of educational informatization.

\section{References}

1. Y. L. Jiang, L. Chen. Enlightenment and Research Comparison between American and Chinese on University Education Informatization. J. E-Education Research, 118, 234 (2012)

2. L. Li, Z. Li. Research on the Development and Driving Factors of Digital Campus in American Colleges and Universities. J. CEI, 17, 24 (2009):

3. Q. L. Yu, X. D. Zheng. The Reality and Challenges of Eduational Informatizationin America's Higher Education. J. Open Education Research, 110, 16 (2010)

4. J. H. Sui, Y. Wang, D. R. Yang. Analysis of the Development Trend of University Education Informatization at Home and Abroad. J. CEI, 5, 24 (2008)

5. B. Q. Liu, S. H. Sun. Conception, Design and Implementation of Digital Campus. University of Science Technology China Press (2014)

6. Y. B. Hu, X. Li, Y. J. Zhao. State of European Union ICT in Education in K-12 Schools. J. CET, 123, 349 (2016) 
7. Q. T. Hu, K. Zheng, N. H. Lin. Development and Transformation of Educational Information. J. CET, 35, 324 (2014)

8. M. Y. Gu. Study and Interpretation on State Planning Out Line for Medium and Long-Term Education Reform and Development (2010 -2020). J. Higher Education, 5, 31 (2010)

9. D. M. Lu. Not Just A Concept on Smart Campus. J. CEN, 29, 12 (2011)

10. H. R. Huang. J. B. Zhang, Y. B. Hu. Smart Campus: The Developing Trends of Digital Campus. J. OER, 12, 18 (2012)

11. Z. T. Zhu, B. He. Wisdom Education: New Realm of Education Information. J. E-Education Research, 5, 236 (2012)

12. X. M. Yang, S. Q. Yu. The Architecture and Key Support Technologies of Smart Education. J. CET, 77, 336 (2015)

13. D. H.Yan, X. M. Chen. The Application of the Internet of Things in Digital Campus. J. MET, 125, 21 (2011)

14. J. Shen. Y. X. Huang. A Preliminary Exploration on Smart Campus and its Construction. J. Fujian Institute of Education, 122, 12 (2011)

15. Y. Bi. Smart Campus Need Resources and Applications. J. CEN, 31, 13(2011)

16. J. He. Study on the Top-level Design and Implementation Measures of Smart City. J. Urban Development Studies, 72, 20 (2013)

17. Z. Y. Lan, C. X. Sun. American Public Policy in Action. Renmin University of China Press (2007)

18. Y. K. Wang. Accurate Understanding of the Top-Level Design of Reform. J. LS, 20, 36 (2012)

19. Y. R. Wang. Process revolution 2.0: Let the Strategic Management of the Landing Process. Peking University press (2011)

20. F. Qiao, L.Y. Fang. On the Construction of Campus Culture in Digital Campus. J. Chongqing Jiaotong University, 100, 7 (2007)

21. Z. C. Song. Educational Culture Theory. J. ER, 4, 33 (2012)

22. Y. J. Sun. Exploratory Thinking on the Universities Campus Public Service. J. HUE, 31, 10 (2015)

23. Information Technology Service Center of ShangXi. Implementation and Service of E-government Public Platform. J. E-Government, 25, 12 (2013)

24. Z. G. Zhang, Y. Tian. Exploration and Practice of the Digital Campus Information Security System. J. ETM, 114, 29 (2012)

25. S. R. Pu, J. Q. Liu. A Probe into the Design and Estimation of Grade -3 Evaluation Index System of Informatization in Universities. J. SNU, 850, 33 (2010) 